\title{
Electrolytic plasma polishing of NiTi alloy
}

\author{
A. Korolyov ${ }^{1}$, A. Bubulis ${ }^{2}$, J. Vèžys ${ }^{3}$, Yu Aliakseyeu ${ }^{4}$, V. Minchenya ${ }^{5}$, V. Niss ${ }^{6}$, D. Markin ${ }^{7}$ \\ ${ }^{1}$ Prospective Technologies Department, State Enterprise Scientific and Technological Park BNTU \\ "Polytechnic", Minsk, Republic of Belarus \\ ${ }^{2}$ Laboratory of Biomechatronics, Institute of Mechatronics, Kaunas University of Technology, \\ Kaunas, Lithuania \\ ${ }^{3}$ Department of Mechanical Engineering, Mechanical Engineering and Design Faculty, Kaunas University \\ of Technology, Kaunas, Lithuania \\ ${ }^{4}$ Science and Technology Park, Belarusian National Technical University, Minsk, Republic of Belarus \\ ${ }^{5}$ Scientific and Technological Park of BNTU "Polytechnic", Minsk, Republic of Belarus \\ ${ }^{6}$ Innovation and Production Center of Medical Equipment and Products of Belarusian National Technical \\ University, Minsk, Republic of Belarus \\ 7"Polymedtech", Minsk, Republic of Belarus \\ ${ }^{1}$ Corresponding author \\ E-mail: ${ }^{1}$ korolyov@park.bntu.by, ${ }^{2}$ algimantas.bubulis@ktu.lt, ${ }^{3}$ joris.vezys@ktu.lt, ${ }^{4}$ y.aliakseyeu@bntu.by, \\ ${ }^{5}$ vlad_minch@mail.ru, ${ }^{6}$ niss@ park.bntu.by, ${ }^{7}$ dmitry.markin@park.bntu.by
}

Received 21 November 2021; received in revised form 14 December 2021; accepted 22 December 2021 DOI https://doi.org/10.21595/mme.2021.22351

Check for updates

Copyright $(2021$ A. Korolyov, et al. This is an open access article distributed under the Creative Commons Attribution License, which permits unrestricted use, distribution, and reproduction in any medium, provided the original work is properly cited.

\begin{abstract}
Nitinol is widely used in the production of medical devices, especially the ones that are designed for minimally invasive treatment, such as stents to restore vascular patency, stent grafts to eliminate aneurysms, and cava filters to trap blood clots. One of the most important characteristics that determines the reliability of the functioning of such products in the human body is the state of the surface layer. The higher the surface quality, the less negative impact is on the circulatory system, the walls of blood vessels and the higher the biological compatibility of the product. Electrochemical polishing methods are mainly used to improve the surface quality of nitinol products. The disadvantage of the applied electrochemical methods is the need to use aggressive electrolytes that contain toxic components, such as hydrofluoric acid, sulfuric acid, perchloric acid, nitric acid, methanol. As an alternative to the existing methods of electrochemical polishing, we have developed electrolytic-plasma polishing (EPP), a new highly efficient process for improving the surface quality of nitinol products. The most important advantage of the method over traditional electrochemical polishing is the use of aqueous salt solutions with a concentration of $4 \%$ as electrolytes. Based on the results of the studies performed, the most rational EPP mode was established, the use of which during polishing of nitinol provides surface cleaning from scale, polishing with a decrease in the roughness parameter Ra by $0.344 \mu \mathrm{m}$ and an increase in pitting potential by $33 \%$.
\end{abstract}

Keywords: nitinol, stent, electrolytic plasma polishing, roughness, corrosion.

\section{Introduction}

The nitinol alloy is a promising biomaterial due to its distinctive properties, such as shape memory, super elasticity, high corrosion resistance and biocompatibility [1]. Through these properties, nitinol is a suitable material for the manufacture of various biomedical products. A number of implants and devices for minimally invasive endovascular surgery, including those intended for restoring the patency of blood vessels in the human body, are made of nitinol, since it retains high strength at significant degrees of deformation. In addition, due to spontaneous surface passivation even at room temperature, nitinol provides sufficient corrosion resistance and biocompatibility for effective use as an implant $[2,3]$.

Recently, various methods have been studied to improve the quality of nitinol surface, based on mechanical polishing and electrochemical polishing [4-7]. The most effective and practical method for improving the surface quality, eliminating surface layer defects, forming a 
homogeneous passive layer, and increasing the corrosion resistance of the nitinol stents surface is a combination of chemical etching and electrochemical polishing [5, 8].

Due to the presence of a stable oxide film on the surface, nitinol is a difficult material for electrochemical technologies. In order to dissolve the oxide film on the nitinol surface, it is necessary to use aggressive electrolytes containing, among other things, toxic components, such as hydrofluoric acid, sulfuric acid, perchloric acid, nitric acid, methanol. One of the most widely used electrolytes in the practice of electrochemical polishing of nitinol is a solution of sulfuric acid in methanol [9]. For polishing austenitic nitinol, an electrolyte is used, which consists of $10 \%$ perchloric and $90 \%$ acetic acids [10]. To polish martensitic nitinol, a solution of $70 \%$ methanol and $30 \%$ nitric acid is used [11]. During the process [12] an electrolyte consisting of sulfuric acid, hydrofluoric acid and ethylene glycol was used. The use of hazardous components for the preparation of electrolytes is the main disadvantage of existing electrochemical methods for improving the surface quality of nitinol products. The use of such electrolytes causes significant harm to the production personnel and the environment.

As an alternative to the existing methods of electrochemical polishing, we have developed electrolytic-plasma polishing (EPP), a new highly efficient process for improving the surface quality of nitinol products. The most important advantage of the method is the use of much less aggressive and toxic electrolytes in comparison with traditional electrochemical polishing. Thus, during the EPP process, aqueous solutions of salts with a concentration of $4 \%$ are used as electrolytes. The current density during EPP is $0,1-0,4 \mathrm{~A} / \mathrm{cm}^{2}$. In addition to surface polishing, the method also provides deburring, cleaning, and increased corrosion resistance of the surface [13]. EPP is widely used in the processes of polishing and surface cleaning of medical devices made of various metallic materials, such as corrosion-resistant steels, titanium alloys, cobalt-chromium alloys $[14,15]$. However, until now, technological regimes and electrolytes have not been developed for processing nitinol products, including products of small section and rigidity used for minimally invasive endovascular surgery.

In this work, using the example of a nitinol stent-element included in the design of a stent-graft, we investigated the effect of EPP on the surface characteristics in order to establish technological parameters that allow achieving a high quality surface treatment, corrosion resistance, provided that the radial stiffness sufficient for its performance is maintained.

\section{Equipment and materials}

The studies were performed on samples of the stent element of an endovascular implantable stent-graft for the abdominal aorta (Fig. 1).

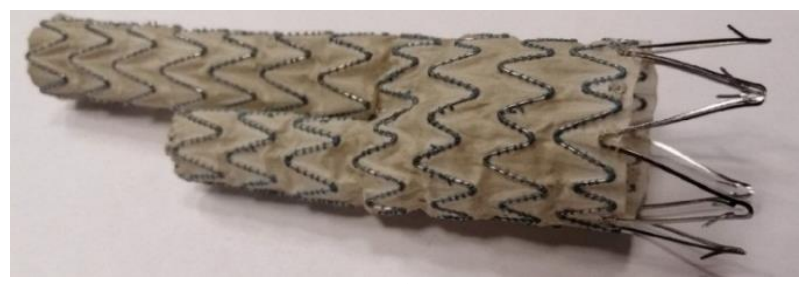

a)

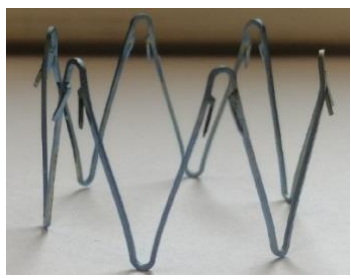

b)

Fig. 1. Outward of endovascular stent-graft for the abdominal aorta and the stent-element of a stent-graft: a) outward of the stent-graft; b) stent-element of the stent-graft

For the manufacture of stent elements, pipes made of C9-10670 nitinol with a diameter of $12 \mathrm{~mm}$ and wall thickness of $0.45 \mathrm{~mm}$ were used. The chemical composition of the material in (wt.\%) in accordance with the ASTM-F2063 standard is presented in Table 1. Laser cutting elements (Rofin Laser) are manufactured. After laser cutting, heat treatment was performed. The total length of the stent-element was $19.5 \mathrm{~mm}$, the outer diameter was $23 \mathrm{~mm}$, and the lamella thickness was $0.45 \mathrm{~mm}$ (Fig. 1(b)). In order to remove slags and metal oxides formed during laser 
cutting, acid etching was performed.

EPP was carried out in an electrolyte based on a $4 \%$ solution of ammonium fluoride in water at a temperature of $90 \pm 3{ }^{\circ} \mathrm{C}$. The samples were processed at a voltage of $300 \mathrm{~V}$ and a current density of $0,15 \mathrm{~A} / \mathrm{cm}^{2}$. The processing times for the samples were 1,3,5 and 7 minutes.

Surface roughness Ra was measured using a MarSurf PS 10 shapemeter. The mass of the stent elements before and after treatment was measured on an Ohaus Pioneer PA214. Measurement of the cross-sectional dimensions of the stent-element lamellae (width $A$, thickness $B$ ) before and after treatment was performed using an Altami metallographic microscope. Radial stiffness tests were carried out on an MSI RX550/650 radial compression force measuring machine. The radial stiffness value was calculated as the ratio of the radial compressive force to the length of the stentelement $(\mathrm{N} / \mathrm{mm})$. Micrographs of the surface of the samples before and after the EPP were obtained using a VEGA II LMU scanning electronic microscope with an INCA350 microanalyzer. To determine the chemical composition of the surface layer, an Inca Energy $350 \mathrm{X}$-ray fluorescence microanalyzer (Oxford Instruments) was used. Corrosion tests were performed by measuring the pitting potential of the obtained samples. For measurements, a PI-50-Pro potentiostat-galvanostat with a connected electrochemical cell was used.

Table 1. C9-10670 alloy chemical composition

\begin{tabular}{|c|c|}
\hline Element & $\%$ (wt.) \\
\hline Nickel & From 54,5 to 57,0 \\
\hline Carbon & 0,05 \\
\hline Cobalt & 0,05 \\
\hline Copper & 0,01 \\
\hline Chromium & 0,01 \\
\hline Hydrogen & 0,005 \\
\hline Iron & 0,05 \\
\hline Niobium & 0,025 \\
\hline Nitrogen + Oxygen & 0,05 \\
\hline Titanium & The rest \\
\hline
\end{tabular}

\section{Results}

The results of measuring the roughness, material removal, radial stiffness, weight change, pitting potential for samples before and after EPP with different durations are presented in Table 2 .

Table 2. Measurement and calculation result

\begin{tabular}{|c|c|c|c|c|c|c|c|}
\hline $\begin{array}{c}\text { Sample } \\
\text { No. }\end{array}$ & $\begin{array}{c}\text { Processing } \\
\text { time, } \\
\text { minutes }\end{array}$ & $\begin{array}{c}\text { Roughness } \\
\text { change } \\
\Delta R a, \mu \mathrm{m}\end{array}$ & $\begin{array}{c}\text { Mass } \\
\text { change } \\
\Delta m, \%\end{array}$ & $\begin{array}{c}\text { Section } \\
\text { change } \\
\Delta S, \mathrm{~mm}^{2}\end{array}$ & $\begin{array}{c}\text { Radial } \\
\text { stiffness, } \\
N / \mathrm{mm}\end{array}$ & $\begin{array}{c}\text { Pitting } \\
\text { potential } \\
\text { Epitt, } \mathrm{mV}\end{array}$ & $\begin{array}{c}\text { A } \times \mathrm{B} \text { section } \\
\text { dimensions, } \\
\mu \mathrm{m}\end{array}$ \\
\hline 1 & 0 & 0,000 & 0,0 & 0,000 & 0,96 & 348 & $520 \times 456$ \\
\hline 2 & 1 & 0,254 & 7,5 & 0,018 & 0,81 & 523 & $501 \times 455$ \\
\hline 3 & 3 & 0,344 & 13,7 & 0,033 & 0,72 & 463 & $494 \times 428$ \\
\hline 4 & 5 & 0,451 & 27,4 & 0,067 & 0,50 & 323 & $444 \times 398$ \\
\hline 5 & 7 & 0,454 & 35,8 & 0,087 & 0,38 & 318 & $431 \times 382$ \\
\hline
\end{tabular}

\section{Surface layer condition}

Electronic photographs of the surfaces of the studied samples of stent-elements before and after EPP are shown in Fig. 2. On the surfaces of the original sample, there are risks obtained during grinding in the process of production of a workpiece (pipe), burr formed during laser cutting as well as mechanical contamination. As a result of EPP, the surface is cleaned, microrelief is achieved after 3 minutes of treatment. As a result of 7 minutes of treatment, a smooth surface is formed, but at the same time the edges are significantly rounded and the size of the product is reduced due to the removal of a layer of great thickness. 


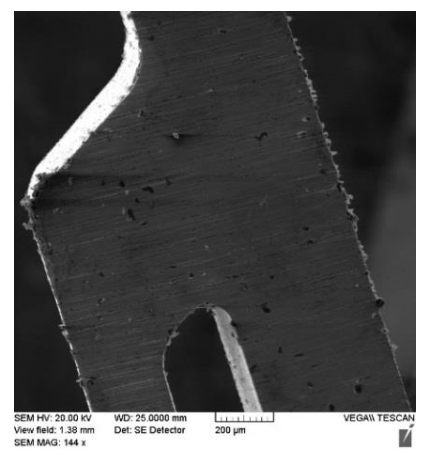

a)

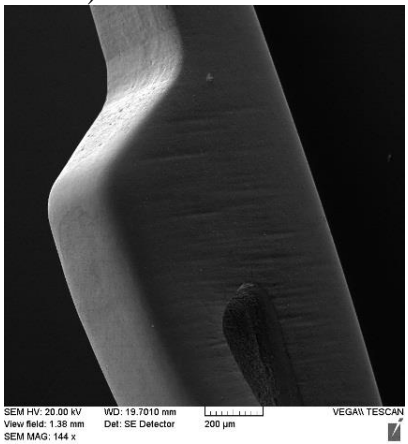

d)

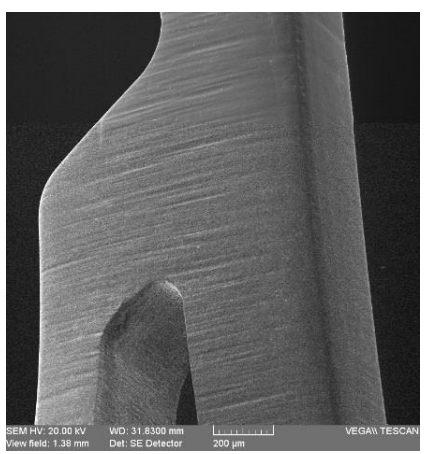

b)

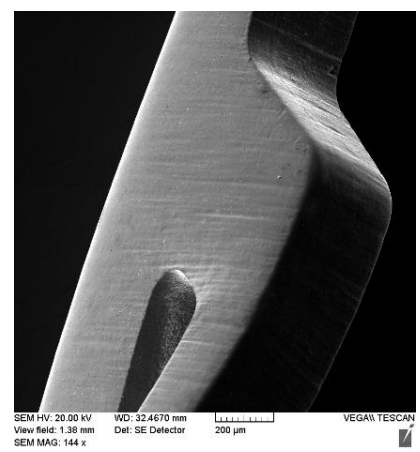

c)

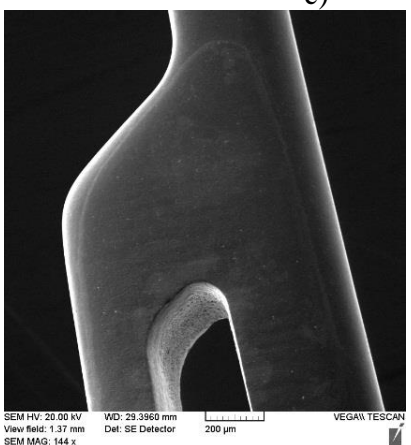

e)

Fig. 2. Outward of surfaces of stent-elements before and after EPP: a) before treatment; b) EPP 1 minute; c) EPP 3 minutes; d) EPP 5 minutes; e) EPP 7 minutes

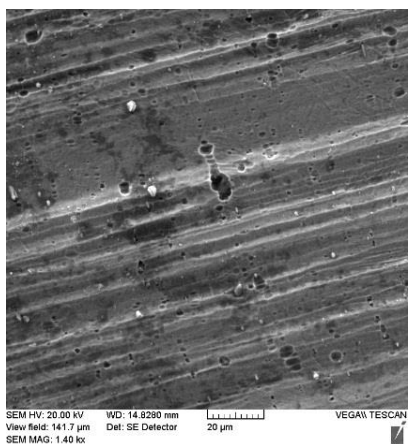

a)

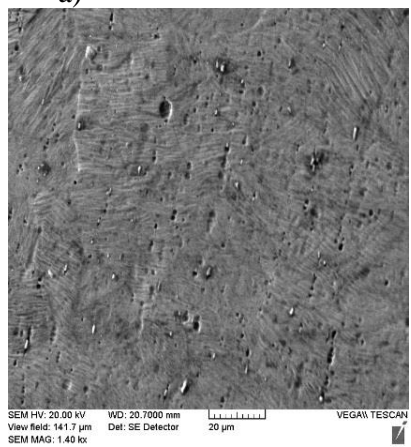

d)

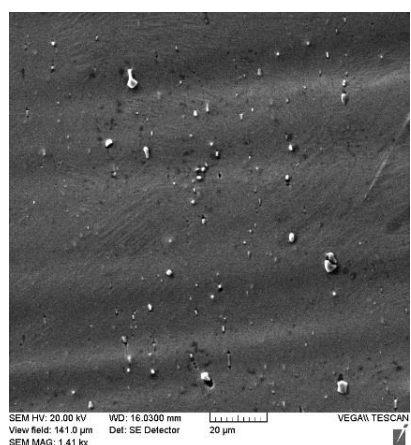

b)

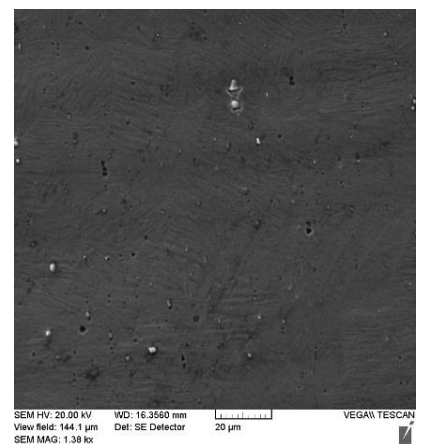

c)

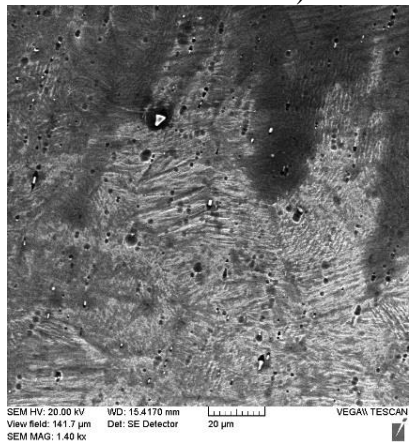

e)

Fig. 3. Stent-element surface condition before and after EPP: a) before treatment;

b) EPP 1 minute; c) EPP 3 minutes; d) EPP 5 minutes; e) EPP 7 minutes 
Photographs of the surface obtained at a higher magnification (Fig. 3) showed the presence of pits on the surface of the initial samples formed as a result of preliminary chemical etching, as well as inclusions in the form of intermetallic phases $\mathrm{TiNi}_{2} \mathrm{O}_{\mathrm{x}}$ and $\mathrm{TiC}$, which appear in the structure of nitinol during its production due to undesirable impurities of oxygen and carbon [16]. Such inclusions affect the temperature of phase transformations in nitinol during the operation of the products, and can also cause a decrease in fatigue strength due to increased cracking $[17,18]$.

As a result of EPP with a duration of 1 minute, the surface layer containing the pits formed in the process of preliminary chemical etching is removed. In this case, intermetallic inclusions appear to a greater extent than on the original surface (Fig. 3(b)). Further processing (Fig. 3(c)) leads to the intermetallic inclusions beginning to be etched out of the alloy structure, with free pores remaining in their place. As a result of EPP lasting 5-7 minutes, the number of intermetallic inclusions significantly decreases, and the number of pores, respectively, increases (Fig. 3(d, e)). In this case, a relief surface characteristic of electrochemical etching is formed with the manifestation of a microstructure.

\section{Surface roughness}

Fig. 4 shows the dependence characterizing the change in surface roughness $\Delta R a$ of the samples under study with an increase in the processing time $t$. The most intense smoothing of microroughness is observed at the initial stage of the surface treatment process with a duration of up to 1 minute. With further processing, the intensity of smoothing is significantly reduced. As a result of processing for 5-7 minutes, the limiting values of $\Delta R a$ are reached.

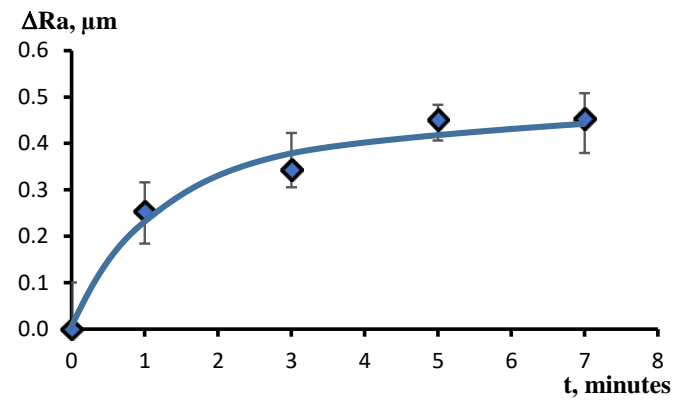

Fig. 4. The effect of EPP duration on surface roughness changes

\subsection{Metal removal}

Metal removal during EPP is proportional to the amount of voltage passed through the sample being processed and depends mainly on the electrolyte temperature, voltage, and immersion depth. All the other things being equal, metal removal depends on the EPP duration $t$. When processing the samples under study, the removal from the surface $m$ ranged from $7,5 \%$ with a duration of 1 minute $35,8 \%$ with a duration of 7 minutes. The dependence of the removal on the duration is shown in Fig. 5.

The dynamics of the change in the profile of the cross-section of the lamellae of the samples under study can be estimated from the micrographs in Fig. 6. In the initial processing period (up to 1 minute), the surface is cleaned, burrs are removed, the highest points of microroughness are smoothed, and the edges are slightly rounded to a radius of $20-36 \mu \mathrm{m}$ (at the initial value of 3-5 $\mu \mathrm{m}$ ). The measurement of profile shape at this stage of processing occurs mainly by reducing its width and height. With further processing, a significant rounding of the edges is observed. The radius of rounding increases with an increase in EPP duration from 32-44 $\mu \mathrm{m}$ at 3 minutes to $105-123 \mu \mathrm{m}$ at 7 minutes. 


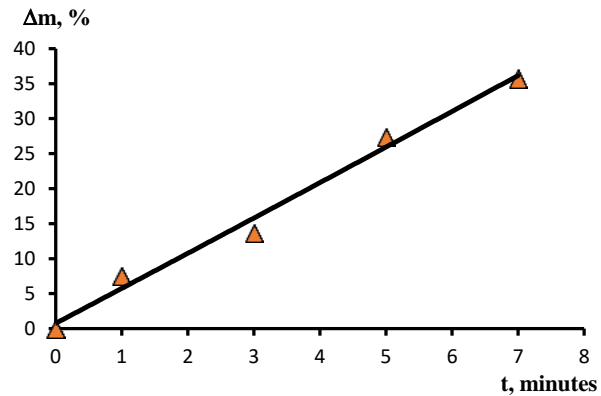

Fig. 5. The dependence of the removal on the duration of processing

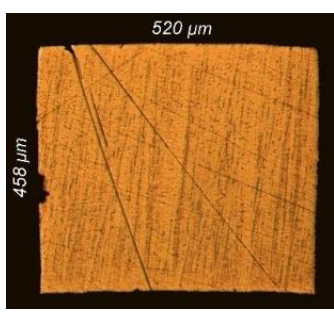

a)

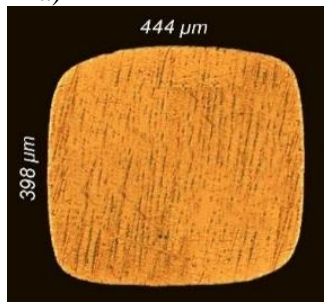

d)

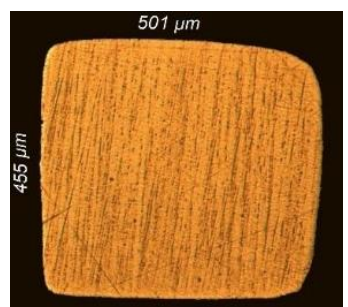

b)

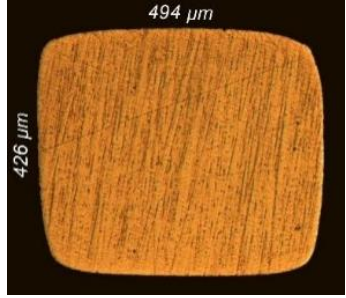

c)

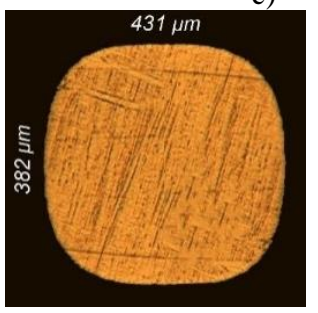

e)

Fig. 6. Change in the cross section of the lamellae of the test samples: a) original; b) 1 minute; c) 3 minutes; d) 5 minutes; e) 7 minutes

\subsection{Radial stiffness}

Radial stiffness determines the ability of the stent to provide a framework function with a force sufficient to resist the elastic action of the vessels, and not exceeding a critical value, leading to rupture of the vessel. Radial stiffness depends primarily on the stent design and heat treatment regimes. The inevitable metal removal, which occurs as a result of technological operations performed after laser cutting of the stent, has a significant effect on reducing the radial stiffness. Therefore, laser cutting is performed taking the allowances for metal removal from the stent surfaces during both preparatory operations (shot blasting, chemical etching) and direct removal during the polishing process into account. The removal reached $29,7 \%$ during the studies on the processes of electrochemical polishing of such products [19, 20].

On the basis of experimental data, it was found that the dependence of the radial stiffness $k$ on the removal $m$ during EPP of the studied stent-elements is clearly linear (Fig. 7). With a removal rate of $35.8 \%$ (corresponding to a processing time of 7 minutes), the radial stiffness decreases by 2.5 times relative to the initial state (from $0.96 \mathrm{~N} / \mathrm{mm}$ to $0.38 \mathrm{~N} / \mathrm{mm}$ ).

\subsection{Corrosion resistance}

Fig. 8 shows the dependence of the pitting potential $E_{\text {pitt }}$ of the surface of the samples on the EPP duration, constructed from the results of potentiodynamic tests. The average values of the pitting potential of the samples after EPP with different durations are from 318 to $523 \mathrm{mV}$. The 
average value of the pitting potential of the initial sample after heat treatment is $348 \mathrm{mV}$. The highest values of $E_{\text {pitt }}$ are achieved with a short EPP duration (up to 3 minutes). In this case, the maximum value of $610 \mathrm{mV}$ was obtained in a series of measurements for a sample treated with a duration of $1 \mathrm{~min}$. Long-term treatment ( $5 \mathrm{~min}$ or more) leads to a significant decrease in the pitting potential to values lower than that of the original sample, and, accordingly, to a decrease in the protective properties of the surface.

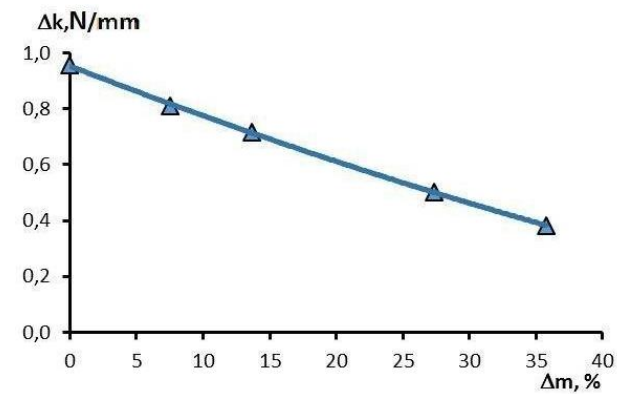

Fig. 7. The effect of metal removal on the change in radial stiffness

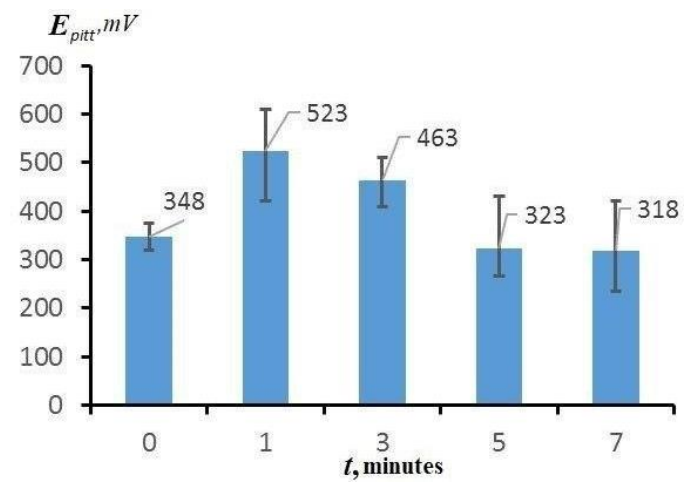

Fig. 8. The effect of the treatment duration on the change in the pitting potential

\subsection{Surface chemical analysis}

Analysis of the chemical composition of the surface of the samples under study showed that as a result of EPP, there is no significant change in the ratio of the main components of the alloy. The ratio of $\mathrm{Ti} / \mathrm{Ni}$ components on the surface of the initial sample is $45,0 / 55,0 \%$, and on the surface of the samples after EPP is 44,3-45,3/54,7-55,7\%.

\section{Discussion}

According to the obtained research results, EPP allows not only to effectively remove the scale formed as a result of heat treatment of stent-elements made of nitinol, improve their surface quality, ensure the rounding of sharp edges, ensure surface uniformity, but also leads to an increase in corrosion resistance. The greatest protective properties of the surface are achieved with a short processing time $(1 \mathrm{~min})$, when the surface is cleaned, deburred, and the highest points of microroughness are smoothed. With this duration, a defective layer with pits formed as a result of preliminary chemical etching is removed, and processing defects in the form of pores freed from intermetallic inclusions are not formed on the surface. Furthermore, as the treatment increases, the pitting potential decreases and, at 5-7 minutes, reaches the values comparable to those of the initial sample.

Chemical analysis of the surface layer showed that EPP does not lead to a change in the 
composition of the surface layer. Thus, an increase in corrosion resistance at the initial stage of EPP (1-3 minutes) is associated not with a change in the ratio of alloy components, but with cleaning of the surface, increase of its uniformity, and smoothing of the microprofile. A significant decrease in corrosion resistance after treatment for 5-7 $\mathrm{min}$ is probably due to the formation of a surface with a large number of pores formed as a result of etching out intermetallic inclusions, which are the center of pitting corrosion.

On the one hand, as a result of EPP, a significant increase in surface quality, corrosion resistance, removal of foreign inclusions, descaling, rounding of sharp edges is provided, and on the other hand, when processing stent elements, an undesirable phenomenon occurs - a decrease in radial stiffness due to metal removal and a decrease in cross-sectional dimensions of their structural elements (lamellas). It was found that with EPP with a duration exceeding 3 minutes, there is a significant decrease in the radial stiffness of the studied stent elements. In addition, after 3 minutes of EPP, the processing efficiency, determined by the ratio of the change in roughness to the mass of the removed material, significantly decreases compared to a processing of a short duration (1-3 minutes).

Comparison of the obtained experimental results shows that the most rational is the EPP mode with a duration of 3 minutes, which provides a high intensity of smoothing of microroughness spots with a decrease in the roughness parameter $R a$ by $0.344 \mu \mathrm{m}$ with a relatively low metal removal $(13,7 \%)$. In this case, the cross-sectional dimensions of the stent-element lamellae decrease by $26-32 \mu \mathrm{m}$ (by 5.0-7.5\%) relative to the initial value, and the edge radii increase to 32-44 $\mu \mathrm{m}$, which does not cause a critical decrease in the radial stiffness of the stent-element and does not lead to disruption of its performance. When using this EPP mode, the pitting potential increases by $115 \mathrm{mV}(33 \%)$ relative to the initial state.

\section{Conclusions}

The results of the studies performed using the example of stent elements showed that EPP is an effective method of cleaning and improving the surface quality, rounding sharp edges and increasing the corrosion resistance of the surface when processing products made of nitinol for minimally invasive surgery. The most rational EPP mode has been established, the use of which, when polishing a nitinol stent-element, provides surface cleaning from scale, polishing with a decrease in the roughness parameter $R a$ by $0.344 \mu \mathrm{m}$ and an increase in the pitting potential by $33 \%$.

Taking the global trends to reduce production processes using hazardous electrochemical technologies and replacing them with more environmentally friendly ones into account, the developed and studied high-tech EPP process seems to be very relevant and promising in the practice of manufacturing medical products from nitinol.

\section{References}

[1] Shabalovskaya S. A., "Corrosion and biocompatibility aspects of nitinol as an implant material," BioMedical Materials and Engineering, Vol. 12, No. 1, pp. 69-109, 2002.

[2] T. Duerig, A. Pelton, and D. Stockel, "An overview of nitinol medical applications," Materials Science and Engineering, Vol. 273-275, pp. 149-160, 1999.

[3] G. S. Firstov, R. G. Vitchev, H. Kumar, B. Blanpain, and J. van Humbeeck, "Surface oxidation of NiTi shape memory alloy," Biomaterials, Vol. 23, No. 24, pp. 4863-4871, Dec. 2002, https://doi.org/10.1016/s0142-9612(02)00244-2

[4] S. A. Shabalovskaya, G. C. Rondelli, A. L. Undisz, J. W. Anderegg, T. D. Burleigh, and M. E. Rettermayr, "The electrochemical characteristics of native Nitinol surfaces," Biomaterials, Vol. 30, pp. 3662-3671, 2009.

[5] S. Shabalovskaya, J. Anderegg, and J. van Humbeeck, "Critical overview of Nitinol surfaces and their modifications for medical applications," Acta Biomaterialia, Vol. 4, No. 3, pp. 447-467, May 2008, https://doi.org/10.1016/j.actbio.2008.01.013 
[6] W. Simka, M. Kaczmarek, A. Baron-Wiecheć, G. Nawrat, J. Marciniak, and J. Żak, "Electropolishing and passivation of NiTi shape memory alloy," Electrochimica Acta, Vol. 55, No. 7, pp. 2437-2441, Feb. 2010, https://doi.org/10.1016/j.electacta.2009.11.097

[7] A. Michiardi, C. Aparicio, J. A. Planell, and F. J. Gil, "Electrochemical behaviour of oxidized NiTi shape memory alloys for biomedical applications," Surface and Coatings Technology, Vol. 201, No. 14, pp. 6484-6488, Apr. 2007, https://doi.org/10.1016/j.surfcoat.2006.12.023

[8] B. Thierry, M. Tabrizian, C. Trepanier, O. Savadogo, and L. H. Yahia, "Effect of surface treatment and sterilization processes on the corrosion behavior of NiTi shape memory alloy," Journal of Biomedical Materials Research, Vol. 51, No. 4, pp. 685-693, Jun. 2000, https://doi.org/10.1002/10974636(20000915)51:4

[9] L. Neelakantan, M. Valtiner, G. Eggeler, and A. W. Hassel, "Surface chemistry and topographical changes of an electropolished NiTi shape memory alloy," Physica Status Solidi, Vol. 207, No. 4, pp. 807-811, 2010.

[10] S. Shabalovskaya, J. Wataha, J. Anderegg, K. Hauch, and J. Cunnick, "Surface treatments and biocompatibility of nitinol," in Proceedings of International Conference of shape memory and superelastic technologies, pp. 367-373, 2004.

[11] S. Shabalovskaya, J. Anderegg, G. Rondelli, W. Vanderlinden, and S. de Feyter, "Comparative in vitro performances of bare Nitinol surfaces.," Bio-Medical Materials and Engineering, Vol. 18, No. 1, pp. 1-14, 2008.

[12] R. Yankov et al., "Reactive plasma immersion ion implantation for surface passivation," Surface and Coatings Technology, Vol. 201, No. 15, pp. 6752-6758, 2007.

[13] Yu. Aliakseyeu, A. Korolyov, and A. Bezyazychnaya, "Electrolyte-plasma treatment of metal materials surfaces," in 14th International Scientific Conference CO-MAT-TECH, 2006.

[14] Y. G. Aliakseyeu, A. Y. Korolyov, V. S. Niss, A. E. Parshuto, and A. S. Budnitskiy, "Electrolyte-plasma polishing of titanium and niobium alloys," Science and Technique, Vol. 17, No. 3, pp. 211-219, May 2018, https://doi.org/10.21122/2227-1031-2018-17-3-211-219

[15] Y. G. Aliakseyeu, A. Y. Korolyov, and V. S. Niss, "Electrolytic-plasma polishing of cobalt-chromium alloys for medical products," Proceedings of the National Academy of Sciences of Belarus, PhysicalTechnical Series, Vol. 64, No. 3, pp. 296-303, Oct. 2019, https://doi.org/10.29235/1561-8358-201964-3-296-303

[16] J. Mentz, M. Bram, H. P. Buchkremer, and D. Stöver, "Improvement of mechanical properties of powder metallurgical NiTi shape memory alloys," Advanced Engineering Materials, Vol. 8, No. 4, pp. 247-252, Apr. 2006, https://doi.org/10.1002/adem.200500258

[17] S.-F. Ou, B.-Y. Peng, Y.-C. Chen, and M.-H. Tsai, "Manufacturing and characterization of NiTi alloy with functional properties by selective laser melting," Metals, Vol. 8, No. 5, p. 342, May 2018, https://doi.org/10.3390/met8050342

[18] J. Chekotu, R. Groarke, K. O. 'Toole, and D. Brabazon, "Advances in selective laser melting of nitinol shape memory alloy part production," Materials, Vol. 12, No. 5, p. 809, Mar. 2019, https://doi.org/10.3390/ma12050809

[19] Z. E. Gellér, K. Albrecht, and J. Dobránszky, "Electropolishing of coronary stents," Materials Science Forum, Vol. 589, pp. 367-372, Jun. 2008, https://doi.org/10.4028/www.scientific.net/msf.589.367

[20] Kao, J.-Y., Lin, S.-Y., Chen, and Y.-S., "Surface processing technology for 316LVM stainless steel stents," Journal of Applied Science and Engineering, Vol. 21, pp. 343-350, 2018, https://doi.org/10.6180/jase.201809_21(3).0005

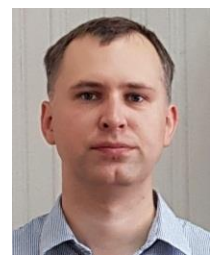

Aleksandr Korolyov, Ph.D. (Engineering), Assistant Professor, Head of Prospective Technologies Department. State Enterprise "Scientific and Technological Park BNTU "Polytechnic" (24, Y. Kolas Str., 220013, Minsk, Republic of Belarus). His current research interests include development of technologies for coating metal materials and electrolytic-plasma polishing of metal products, development of medical products and technologies for their production. In this paper was responsible for co-analysis of the surface chemical composition of the test samples showed that the ratio of the main alloy components of the EPP did not change significantly. 


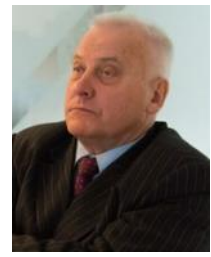

Algimantas Bubulis - author and coauthor of over 200 scientific articles, 70 scientific inventions, $45 \mathrm{LR}$ patents and one EU patent of precision mechanics and mechatronics areas, three monographs published in Lithuanian, English and Russian languages, and a coauthor of the textbook for students. 1998-2011 Vice president in association of "Vibrotechnika", the member of Lithuanian acoustics union (2011). Scientific committee member for international scientific conferences "Vibroengineering", "MSM". Scientific committee member for the scientific journal "JVE Vibroengineering" and "Vibracija $\mathrm{V}$ technike i technologiji" (Ukrainian National Academy of Sciences), editorial board member of the Israel Academy of Sciences, an also member of the Independent Scientific Academy. In this paper proposed the structural elements of the stents, the shape of the whole frame, determined the resistance characteristics.

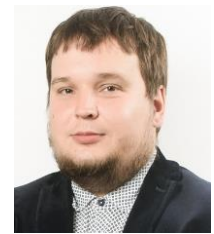

Joris Vèžys has defended his Ph.D. thesis of mechanical engineering in Kaunas University of Technology at the topic "Development of the device for the research of magnetorheological fluids properties". He has participated in 5 international conferences, has 13 international publications, 4 of them with impact factor. Co-author of 3 Lithuanian patents. In this paper was responsible for a radial stiffness was found to determine the ability of the stent to perform a skeletal function with a force sufficient to resist the elastic effects of the vessels and did not exceed the critical value that causes the vessel to rupture.

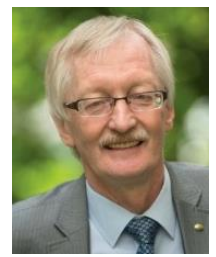

Yuri Aliakseyeu received the Ph.D. degree in engineering in Belarusian National Technical University, Minsk, Republic of Belarus in 1988. Now works as the General director of the science and technology park - Vice-rector Belarusian National Technical University, Minsk, Belarus. His current research interests include development of technologies for obtaining hard-alloy ceramic materials, technologies for coating metal materials and electrolytic-plasma polishing of metal products, development of medical products and technologies for their production, research of the method of thermal relaxation differential spectrometry to study the total thermal resistance in products of power semiconductor and optoelectronics. In this paper was responsible for the metal removal during EPP was found to be proportional to the amount of stress passed through the treated sample and was largely dependent on the electrolyte temperature, voltage, and immersion depth.

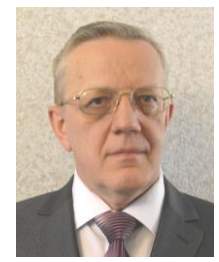

Vladimir Minchenya received the Ph.D. degree in engineering in Belarusian National Technical University, Minsk, Republic of Belarus in 1987. Prof. of Belarusian National Technical University. Chief Researcher of the Scientific and Technological Park of BNTU "Polytechnic". Honored Educationist of the Republic of Belarus. Corresponding Member of the International Academy of Information Technologies. Published over 300 scientific articles, 7 monographs. Has over 150 patents for inventions. Research interests include the fields of ultrasonic engineering and technology, medical and measuring technology, research of the method of thermal relaxation differential spectrometry for the study of total thermal resistance in products of power semiconductor and optoelectronics. In this paper was responsible for the review and found that the high-tech ERP process developed and researched appears to be highly relevant and promising in the production of nitinol medicinal products, given the global trend to reduce production processes using hazardous electrochemical technologies and replace them with more environmentally friendly ones. 


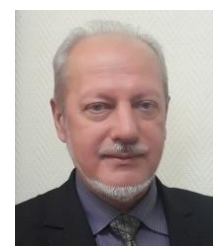

Vladimir Niss received the Ph.D. degree in engineering in Belarusian National Technical University, Minsk, Republic of Belarus in 1988. Now works as the Head of the Innovation and Production Center of Medical Equipment and Products of Belarusian National Technical University. His current research interests include development of technologies for obtaining hard-alloy ceramic materials, technologies for coating metal materials and electrolytic-plasma polishing of metal products, development of a method of thermal relaxation differential spectrometry to study the total thermal resistance in power semiconductor and optoelectronic products, development of medical products and technologies for their production. In this paper was responsible for preparing and describing the results of measurements of sample roughness, material removal, radial stiffness, weight change, pitting potential before and after EPP are presented for different durations.

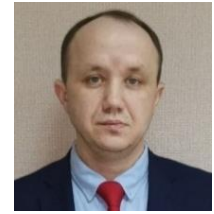

Dmitry Markin Director, "Polymedtech" LLC (37/1, Surganova Str., 220013, Minsk, Republic of Belarus. In this paper was responsible for the analysis of the surface chemical composition of the investigated samples was performed, the ratio of the main alloy components of EPP was determined, and the participants of the endovascular implantable stent-graft for abdominal aortic stent element were studied. 